\title{
Quality of Life and Anxiety Status following Donor Liver Trans- plantation
}

\author{
Ayten Saracoglu ${ }^{1 *}$, Fisun Bulutcu ${ }^{1}$, Levent Oklu ${ }^{1}$, Ercument Yentur ${ }^{1}$, Yildiray Yuzer ${ }^{2}$, Yaman Tokat ${ }^{2}$ \\ ${ }^{1}$ Department of Anesthesiology and Reanimation Marmara, University School of Medicine, Turkey \\ ${ }^{2}$ Department of General Surgery Bilim, University School of Medicine, Turkey \\ *Corresponding author: Ayten Saracoglu, Assoc. Prof. M.D. DESA, Department of Anesthesiology and Re- \\ animation Marmara, University School of Medicine, Florence Nightingale Hospital Abide-i Hurriyet Cad. No: \\ 166 Caglayan Sisli Istanbul, Turkey, Tel: +90-(212)-375-65-65, Fax: +90-(212)-224-49-82
}

\begin{abstract}
Study objective: Anxiety disorder, which is encountered in surgical patients receiving general anesthesia is a psychological and physical condition, characterized by sudden onset of hazard perception and extensive fear, and may lead to panic disorder. In this study, we aimed to determine anxiety levels of liver transplantation donors via a questionnaire and reveal their quality of life and anxiety status during the $1^{\text {st }}$ postoperative day and month.
\end{abstract}

Design: Prospective observational study.

Setting: In the critical care.

Patients: Following the Ethics Committee approval, forty subjects of both sexes, between the ages of 18 and 75 years, who were on the list of liver transplant donors were included in the study.

Interventions: A 10-item anxiety and quality of life questionnaire was prepared using scales applied to surgical patients, such as the Amsterdam Preoperative Anxiety and Information Scale for preoperative anxiety, the Spielburger State-Trait Anxiety and Inventory and the Profile of Mood States on the 1st postoperative day and month.

Measurements: Data regarding the donor's age, sex, marital status, educational background, history of previous surgeries, the degree of affinity between donor and the recipient, number and age of their children, and duration of patient's disease were recorded.

Main results: On the first day and in the first month, the total score on questions "I am worried about anesthesia" was significantly lower than the total scores on the questions "I am worried about the success of the surgical procedure" and "I am worried about the risk of anesthesia-related mortality" ( $p$ $=0.007$ and $p=0.001$, respectively).
Conclusions: Many living donors are motivated to make their decision on this procedure in a short time. We believe that allocating more time to informing patients and donors and holding information meetings on anesthesia and surgical procedures at intervals may be beneficial.

\section{Keywords}

Liver transplantation, Anxiety, Quality of life, Survey

\section{Introduction}

Anxiety disorder in patients after anesthesia, is a psychological and physical condition which is characterized by sudden onset of hazard perception and extensive fear and can lead to panic disorder. The first living donor liver transplantation (LDLT) was performed in 1989 and LDLT has recently attained a stable place in surgical treatment of the end-stage liver diseases [1].

Living organ donation has a significant risk of morbidity and mortality without having a surgical gain. In several studies, it was shown that $40 \%$ of donors experience a complication [2]. Most of them are categorized as Clavien grade I or II and 95\% improvement is achieved in the first year after surgery [3]. However donor liver transplantation has a potential for lifelong impact on donors' both psychosocial and medical status [4]. Besides the Japanese Liver Transplantation Society reported that, in the first year following surgery, $10 \%$ of donors might still have several physical symptoms [5].

Donor's decision requires a strong emotional and mental anguish including their responsibility and rela-

Citation: Saracoglu A, Yuzer F, Oklu L, Yentur E, Yuzer Y, et al. (2018) Quality of Life and Anxiety Status following Donor Liver Transplantation. Int J Anesthetic Anesthesiol 5:076. doi.org/10.23937/23774630/1410076

Accepted: October 29, 2018: Published: October 31, 2018

Copyright: (c) 2018 Saracoglu A, et al. This is an open-access article distributed under the terms of the Creative Commons Attribution License, which permits unrestricted use, distribution, and reproduction in any medium, provided the original author and source are credited. 
tionships between family members [6,7]. Therefore the team should pay attention for their perioperative circumstances.

The improvement of the survival rates of donors have increased the interest for measuring the quality of life and anxiety scores [8,9]. Previous studies concluded that there is a significant correlation between the impaired quality of life and psychiatric morbidity [10]. Despite those adverse effects, psychological changes experienced by the liver transplantation patients might be ignored. In order to prevent such changes and decrease the rate of mortality related to patient's psychological condition, psychological care units have begun to be established in transplant centers [11,12]. Although previous studies in this field primarily focused on liver transplant recipients, there is an increase in the researches regarding the quality life and mood changes of donors, such as anxiety and depression $[13,14]$.

There are some scales used for measuring perioperative anxiety level. The Amsterdam Preoperative Anxiety and Information Scale (APAIS) [15], the Spielburger State-Trait Anxiety and Inventory (STAI) [16], and Anxiety-Visual Analog Scale (VAS) enable quantitative measurement of anxiety level. Additionally, The Profile of Mood States (POMS) [5] is the scale used for patients undergoing hepatic transplantation. The aim of the present study was to determine anxiety levels of liver

Table 1: The survey questions.

Kindly give the answer which seems to describe your present feelings best

$1=$ not at all $2=$ somewhat $3=$ moderately so $4=$ very much so $5=$ completely

1. I was worried about anesthesia

$1 . .2 \ldots 3 \ldots 4 \ldots 5$

2. I wanted to be informed as much as possible about anesthesia

$1 \ldots 2 \ldots 3 \ldots 4 \ldots 5$

3. I was worried about the success of the surgical procedure

$1 \ldots 2 \ldots 3 \ldots 4 \ldots 5$

4. I am worried about the recipient's risk of anesthesia-related mortality

$1 . .2 \ldots 3 \ldots 4 \ldots 5$

5. I wanted to be informed as much as possible about the surgical procedure

$1 \ldots 2 \ldots 3 \ldots 4 \ldots 5$

6. I feel secure

$1 \ldots 2 \ldots 3 \ldots 4 \ldots 5$

7. I am in sense of regret

$1 \ldots 2 \ldots 3 \ldots 4 \ldots 5$

8. I was worried about my future

$1 \ldots 2 \ldots 3 \ldots 4 \ldots 5$

9. I feel relaxed

$1 \ldots 2 \ldots 3 \ldots 4 \ldots 5$

10. Do you have?

Pain (0-100):

Nausea and vomiting: donors and reveal their quality of life and anxiety status during the $1^{\text {st }}$ postoperative day and the $1^{\text {st }}$ postoperative month via aforementioned scales and the questionnaire prepared within the scope of the study.

\section{Materials and Methods}

Following the approval of the Hospital Ethics Committee and patients' written informed consents, 40 subjects of both sexes, between 18 and 75 years, on the list of liver transplant donors were included in the study. Patients taking psychotropic medication and having a psychiatric or neurological disease or having difficulty in understanding the principles of study were excluded. Patients' data including age, sex, marital status, number and age of their children, educational background, history of previous surgeries, and the degree of affinity with the recipient and duration of disease suffered by the recipient were recorded. On the $1^{\text {st }}$ day and $1^{\text {st }}$ month, patients were asked to fill in a 10 -item questionnaire (Table 1). Patients scored the first nine questions using a five-level Likert scale. Patients were not administered any anxiolytics either in preoperative or in postoperative period. Patients' ratings on questions related to anesthesia or surgery were separately calculated and compared. Also, the presence of nausea and vomiting, and the pain levels were determined and recorded. Patients rated their pain intensity on a $100 \mathrm{~mm}$ Visual Analogue Scale (VAS).

\section{Statistical Method}

Statistical analyses were conducted with the Statistical Package for the Social Sciences (SPSS) version 21.0. The Kruskal-Wallis test and the Mann-Whitney $u$ test were used for analyzing qualitative data while repeated measurements were evaluated using the Wilcoxon test.

\section{Results}

Three patients were excluded from the study and the data of 37 patients were analyzed. There was no significant difference between patients in regard to patient demographics, educational and marital status (Table 2). The score on the question [I wanted to have information about anesthesia] was significantly higher on the $1^{\text {st }}$ day compared to the $1^{\text {st }}$ month $(p=0.004)$. There was not a significant difference between the $1^{\text {st }}$ day and $1^{\text {st }}$ month regarding the scores of the other questions. The scores on the question of 'Pain Score' was significantly higher on the $1^{\text {st }}$ day than in the $1^{\text {st }}$ month $(p<0.05)$. The rates of nausea and vomiting did not show any significant difference in the $1^{\text {st }}$ day and $1^{\text {st }}$ month $(p>0.05)$ (Table 3). On the $1^{\text {st }}$ day and in the $1^{\text {st }}$ month, the total score on the questions [I am worried about anesthesia] and [I wanted to be informed as much as possible about anesthesia] was significantly lower than the total score on the questions [ $1 \mathrm{am}$ worried about the success of the surgical procedure] and [I wanted to be informed as much as possible about surgical procedure] ( $p<$ 0.05 ) (Table 4). Additionally, on the $1^{\text {st }}$ day and in the 
Table 2: Patient demographics, educational and marital status (mean $\pm \mathrm{sd}$ ).

\begin{tabular}{|c|c|c|c|c|}
\hline & & Min & Max & n (\%) \\
\hline Age (year) & & 19 & 5 & $33.57 \pm 9.05$ \\
\hline \multirow{2}{*}{ Gender } & Female & & & $14(37.8 \%)$ \\
\hline & Male & & & $23(62.2 \%)$ \\
\hline \multirow{3}{*}{ Education level } & Primary school & & & $8(21.6 \%)$ \\
\hline & High school & & & $11(29.7 \%)$ \\
\hline & University & & & $18(48.6 \%)$ \\
\hline \multirow{2}{*}{ Marital status } & Single & & & $18(48.6 \%)$ \\
\hline & Married & & & $19(51.4 \%)$ \\
\hline \multirow{2}{*}{ Children } & No & & & $19(51.4 \%)$ \\
\hline & Yes & & & $18(48.6 \%)$ \\
\hline \multirow{3}{*}{ Etiology } & Alcohol & & & $6(16.2 \%)$ \\
\hline & Infection & & & $20(54.1 \%)$ \\
\hline & Other & & & $11(29.7 \%)$ \\
\hline \multirow{2}{*}{ Previous surgery } & No & & & $20(54.1 \%)$ \\
\hline & Yes & & & $17(45.9 \%)$ \\
\hline \multirow{2}{*}{ Degree of kinship } & $1^{\text {st }}$ degree & & & $9(24.3 \%)$ \\
\hline & $2^{\text {nd }}$ degree or more & & & $28(75.7 \%)$ \\
\hline Length of disease (year) & & 2 months & 20 years & $5.29 \pm 5.44$ \\
\hline
\end{tabular}

Table 3: The evaluation of survey questions, pain scores and incidence of nausea and vomiting (mean $\pm \mathrm{sd}$ ).

\begin{tabular}{|c|c|c|c|c|c|c|}
\hline \multirow{3}{*}{ I was worried about anesthesia } & \multirow{3}{*}{$\begin{array}{l}1^{\text {st }} \text { day } \\
1^{\text {st }} \text { month }\end{array}$} & \multicolumn{3}{|c|}{ min-max } & \multirow{3}{*}{$\begin{array}{l}\mathbf{n}(\%) \\
1.70 \pm 1.10 \\
1.4 \pm 0.7\end{array}$} & \multirow{3}{*}{$\begin{array}{l}\mathbf{p} \\
0.101\end{array}$} \\
\hline & & 1 & - & 4 & & \\
\hline & & 1 & - & 3 & & \\
\hline \multirow{2}{*}{ I wanted to be informed as much as possible about anesthesia } & $1^{\text {st }}$ day & 1 & - & 5 & $1.68 \pm 1.03$ & \multirow{2}{*}{0.004} \\
\hline & $1^{\text {st }}$ month & 1 & - & 5 & $1.24 \pm 0.76$ & \\
\hline \multirow{2}{*}{ I was worried about the success of the surgical procedure } & $1^{\text {st }}$ day & 1 & - & 5 & $2.11 \pm 1.10$ & \multirow{2}{*}{0.254} \\
\hline & $1^{\text {st }}$ month & 1 & - & 5 & $1.89 \pm 1.37$ & \\
\hline \multirow{2}{*}{ I am worried about the recipient's risk of anesthesia-related mortality } & $1^{\text {st }}$ day & 1 & - & 5 & $2.81 \pm 1.45$ & \multirow{2}{*}{0.106} \\
\hline & $1^{\text {st }}$ month & 1 & - & 5 & $2.46 \pm 1.41$ & \\
\hline \multirow{2}{*}{ I wanted to be informed as much as possible about the surgical procedure } & $1^{\text {st }}$ day & 1 & - & 5 & $2.19 \pm 1.49$ & \multirow{2}{*}{0.164} \\
\hline & $1^{\text {st }}$ month & 1 & - & 5 & $2.51 \pm 1.52$ & \\
\hline \multirow{2}{*}{ I feel secure } & $1^{\text {st }}$ day & 1 & - & 5 & $4.16 \pm 1.36$ & \multirow{2}{*}{0.755} \\
\hline & $1^{\text {st }}$ month & 0 & - & 5 & $4.27 \pm 1.43$ & \\
\hline \multirow{2}{*}{ I was worried about my future } & $1^{\text {st }}$ day & 1 & - & 5 & $2.00 \pm 1.18$ & \multirow{2}{*}{0.083} \\
\hline & $1^{\text {st }}$ month & 1 & - & 5 & $1.59 \pm 0.93$ & \\
\hline \multirow{2}{*}{ Pain score } & $1^{\text {st }}$ day & 0 & - & 100 & $16.22 \pm 8.77$ & \multirow{2}{*}{0} \\
\hline & $1^{\text {st }}$ month & 0 & - & 100 & $3.78 \pm 4.63$ & \\
\hline \multirow{2}{*}{ Nausea and vomiting } & $1^{\text {st }}$ day & & & & $4(10.8 \%)$ & \multirow{2}{*}{0.125} \\
\hline & $1^{\text {st }}$ month & & & & $0(0.0 \%)$ & \\
\hline Wilcoxon test & & & & & & \\
\hline
\end{tabular}

Table 4: The comparison of Anesthesia Sum and Surgery Sum (mean $\pm s d)$.

\begin{tabular}{|l|l|l|l|}
\hline & Anesthesia Sum & Surgery Sum & $\mathbf{p}$ \\
\hline $\mathbf{1}^{\text {st }}$ day & $3.38 \pm 1.83$ & $4.30 \pm 1.87$ & $\mathbf{0 . 0 0 7}$ \\
\hline $\mathbf{1}^{\text {st }}$ month & $2.68 \pm 1.13$ & $4.41 \pm 2.41$ & $\mathbf{0}$ \\
\hline
\end{tabular}

Table 5: The comparison of question 1 and 4.

\begin{tabular}{|l|l|l|l|}
\hline & Question 1 & Question 4 & p \\
\hline $\mathbf{1}^{\text {st }}$ day & $1.70 \pm 1.10$ & $2.81 \pm 1.45$ & $\mathbf{0 . 0 0 1}$ \\
\hline $\mathbf{1}^{\text {st }}$ month & $1.43 \pm 0.69$ & $2.46 \pm 1.41$ & $\mathbf{0 . 0 0 1}$ \\
\hline
\end{tabular}

Question 1: I was worried about anesthesia.

Question 4: I was worried about the recipient's risk of life depending on anesthesia.

$1^{\text {st }}$ month, the total score on the question [I am worried about anesthesia] was significantly lower than the score on the question [I am worried about the recipient's risk of anesthesia-related mortality] ( $<$ 0.05) (Table 5).
The scores given to the questions [I am worried about the recipient's risk of anesthesia-related mortality], [I feel secure] and [I was worried about my future] did not show any difference according to sex, age, marital status, whether they have children or not, educational background, whether they had operation before or not, the degree of kinship, and the reasons of referral ( $p>0.05)$.

The scores on the questions [I am worried about anesthesia] and [I wanted to be informed as much as possible about anesthesia] showed no significant difference on the $1^{\text {st }}$ day and $1^{\text {st }}$ month regarding patients' sex, age, marital status, educational background, degree of kinship and reasons of the referral, whether they have children or not, and whether they had operation previously or not $(p>0.05)$ (Table 6).

There was no significant difference between the 
Table 6: Comparison of the scores on questions related with anesthesia (mean $\pm s d$ ).

\begin{tabular}{|c|c|c|c|c|c|}
\hline & & \multicolumn{2}{|l|}{$1^{\text {st }}$ day } & \multicolumn{2}{|l|}{$1^{\text {st }}$ month } \\
\hline & & $\mathbf{r}$ & $\mathbf{p}$ & $\mathbf{r}$ & $\mathbf{p}$ \\
\hline \multirow{2}{*}{ Gender } & Female & $3.13 \pm 1.52$ & \multirow{2}{*}{0.588} & $2.57 \pm 0.79$ & \multirow{2}{*}{0.912} \\
\hline & Male & $3.79 \pm 2.26$ & & $2.86 \pm 1.56$ & \\
\hline Age & & -0.19 & 0.261 & -0.009 & 0.956 \\
\hline \multirow{2}{*}{ Marital status } & Single & $3.50 \pm 1.95$ & \multirow{2}{*}{0.532} & $2.78 \pm 1.00$ & \multirow{2}{*}{0.283} \\
\hline & Married & $3.26 \pm 1.76$ & & $2.58 \pm 1.26$ & \\
\hline \multirow{2}{*}{ Children } & No & $3.39 \pm 1.88$ & \multirow{2}{*}{0.844} & $2.78 \pm 1.40$ & \multirow{2}{*}{1} \\
\hline & Yes & $3.37 \pm 1.83$ & & $2.58 \pm 0.84$ & \\
\hline \multirow{3}{*}{ Educational Level } & Primary school & $2.88 \pm 1.81$ & \multirow{3}{*}{0.335} & $2.75 \pm 1.16$ & \multirow{3}{*}{0.801} \\
\hline & High school & $3.09 \pm 1.58$ & & $2.45 \pm 0.82$ & \\
\hline & University & $3.78 \pm 1.99$ & & $2.78 \pm 1.31$ & \\
\hline \multirow{2}{*}{ Previous surgery } & No & $2.88 \pm 1.54$ & \multirow{2}{*}{0.129} & $2.82 \pm 1.42$ & \multirow{2}{*}{0.816} \\
\hline & Yes & $3.80 \pm 1.99$ & & $2.55 \pm 0.83$ & \\
\hline \multirow{2}{*}{ Degree of kinship } & $1^{\text {st }}$ degree & $3.32 \pm 1.76$ & \multirow{2}{*}{0.954} & $2.71 \pm 1.15$ & \multirow{2}{*}{0.532} \\
\hline & $2^{\text {nd }}$ degree and more & $3.56 \pm 2.13$ & & $2.56 \pm 1.13$ & \\
\hline \multirow{3}{*}{ Etiology } & Alcohol & $2.33 \pm 0.52$ & \multirow{3}{*}{0.222} & $2.17 \pm 0.41$ & \multirow{3}{*}{0.086} \\
\hline & Infection & $3.80 \pm 1.88$ & & $3.05 \pm 1.36$ & \\
\hline & Other & $3.18 \pm 2.04$ & & $2.27 \pm 0.65$ & \\
\hline \multicolumn{2}{|c|}{ Length of disease (year) } & -0.188 & 0.264 & 0.088 & 0.604 \\
\hline
\end{tabular}

Kruskal-Wallis/Mann-whitney u test/Spearman correlation.

Table 7: Comparison of the scores on questions related with surgical prosedure (mean $\pm s d$ ).

\begin{tabular}{|c|c|c|c|c|c|}
\hline & & \multicolumn{2}{|c|}{$1^{\text {st }}$ day } & \multicolumn{2}{|c|}{$1^{\text {st }}$ month } \\
\hline & & $\mathbf{r}$ & $\mathbf{p}$ & $\mathbf{r}$ & $p$ \\
\hline \multirow{2}{*}{ Gender } & Female & $3.83 \pm 1.59$ & \multirow{2}{*}{0.079} & $3.78 \pm 1.7$ & \multirow{2}{*}{0.134} \\
\hline & Male & $5.07 \pm 2.09$ & & $5.43 \pm 3.06$ & \\
\hline Age & & 0.018 & 0.917 & 0.024 & 0.886 \\
\hline \multirow{2}{*}{ Marital status } & Single & $3.78 \pm 1.86$ & \multirow{2}{*}{0.062} & $4.06 \pm 1.98$ & \multirow{2}{*}{0.552} \\
\hline & Married & $4.79 \pm 1.78$ & & $4.74 \pm 2.77$ & \\
\hline \multirow{2}{*}{ Children } & No & $4.5 \pm 1.65$ & \multirow{2}{*}{0.38} & $4.67 \pm 2.61$ & \multirow{2}{*}{0.574} \\
\hline & Yes & $4.11 \pm 2.08$ & & $4.16 \pm 2.24$ & \\
\hline \multirow{3}{*}{ Educational level } & Primary school & $3.88 \pm 1.89$ & \multirow{3}{*}{0.051} & $3.13 \pm 2.1$ & \multirow{3}{*}{0.058} \\
\hline & High school & $3.36 \pm 1.36$ & & $4.27 \pm 2.8$ & \\
\hline & University & $5.06 \pm 1.89$ & & $5.06 \pm 2.15$ & \\
\hline \multirow{2}{*}{ Previous surgery } & No & $4.24 \pm 1.82$ & \multirow{2}{*}{0.888} & $4.12 \pm 2.64$ & \multirow{2}{*}{0.323} \\
\hline & Yes & $4.35 \pm 1.95$ & & $4.65 \pm 2.23$ & \\
\hline \multirow{2}{*}{ Degree of kinship } & $1^{\text {st }}$ degree & $4.21 \pm 1.69$ & \multirow{2}{*}{0.841} & $4.43 \pm 2.46$ & \multirow{2}{*}{0.884} \\
\hline & $2^{\text {nd }}$ degree and more & $4.56 \pm 2.46$ & & $4.33 \pm 2.4$ & \\
\hline \multirow{3}{*}{ Etiology } & Alcohol & $3.83 \pm 1.33$ & \multirow{3}{*}{0.863} & $5.33 \pm 1.63$ & \multirow{3}{*}{0.239} \\
\hline & Infection & $4.4 \pm 2.04$ & & $4.5 \pm 2.8$ & \\
\hline & Other & $4.36 \pm 1.91$ & & $3.73 \pm 1.9$ & \\
\hline Length of disease (year) & & 0.076 & 0.833 & 0.036 & 0.833 \\
\hline
\end{tabular}

Kruskal-Wallis/Mann-whitney u test/Spearman correlation.

scores given to the questions [I am worried about the success of the surgical procedure] and [I wanted to be informed as much as possible about surgical procedure] regarding sex, age, marital status, whether patients have children or not, their educational background, history of previous surgeries, the degree of kinship, and the reasons of referral $(p>0.05)$ (Table 7).

\section{Discussion}

This study has revealed that liver donors are more anxious about anesthesia than surgery, and give more importance to the survival of liver recipients. Medical teams working in transplantation units are more conscious today and giving more importance to carrying psychological analyses for patients in the perioperative period $[17,18]$. A previous questionnaire survey including 400 patients has indicated that $81 \%$ of the patients suffered from preoperative anxiety [19]. The fear of postoperative pain was identified as the most common source of preoperative anxiety (84\%) which was followed by the fear of the failure of postoperative recovery (64.8\%), with nausea and vomiting. In the same study, the anxiety rate was found to be higher in female patients. Nevertheless, in the present study donor anxiety related to his/her own life and recipient's life did show a change regarding sex, age, marital status, having children, educational status, degree of kinship and reason of the referral or whether they had operation 
earlier. Although Jin, et al. [13] reported that especially age and sex affected the level of donor's postoperative quality of life, no correlation was found between the quality of life and the aforementioned variables in the present study. Sleep disorders were also reported [20].

This study differs from other similar studies in that it compares the anxiety of anesthesia with surgery. The rate of patients who were anxious and wanted to have more information about anesthesia was significantly higher than the rate of patients who were anxious and wanted to have more information about the surgery. However, sex or other factors did not have any influence on the anxiety level. In our study, patients counted on the surgical team and that might be one of the factors decreasing the anxiety against potential surgical complications. The score on the question 'I wanted to be informed about anesthesia' was significantly higher on the $1^{\text {st }}$ day compared to the $1^{\text {st }}$ month. Therefore, it can be concluded that patients' anxiety level can be decreased by providing them with accurate information on the surgical procedure in the early preoperative period.

Donors are individuals who are both mentally and physically healthy. The idea of helping a person in need by means of a surgery may cause anxiety for a healthy person. However, the donors in our study had lower anxiety about their surgeries compared to the anxiety they had about anesthesia-related mortality risk of recipients. It may be correlated with that all donors were at a certain level related to recipients. On the other hand, the donors included in our study thought that recipients were in the end-stage of the disease and they are the only opportunity for those recipients. That may be the reason why they were more concerned about recipients. At the same time, that way of thinking may have probably led donors to ignore potential surgical complications and health problems which they may suffer from due to transplant surgery. As stated in Weng, et al. [21] donors might have felt that they could deal with potential complications as they were in good health. It was, however, reported that one third of donors were uncertain about hepatectomy and that uncertainty played a role in development of anxiety [22]. Those donors who do not have enough time to make a decision may show depression symptoms [23]. On the other hand the survival of the recipient play an active role on donor's unwillingness to donate again [24]. According to DuBay, et al. [25] researchers should pay more attention to the donors who have been diagnosed with psychiatric disorders or who are young or have had further education.

One limitation of the study concerns the analysis of anxiety. To put in another way, in this study patients' anxiety levels were analyzed only in the postoperative period and preoperative anxiety was not considered. As donors had many questions and uncertainties on their mind in the preoperative period and were supposed to make decisions within very limited time, we did not want to have any influence on their decision making process. For this reason, we decided that analyzing anxiety in the postoperative period would bear more elective results for the study.

Although the anxiety developing in patients who received anesthesia for surgical procedures is functional and healthy to a certain extent, high perioperative anxiety is found to be correlated with not only increased morbidity and mortality but also increased need for anesthetics. Also, it has a direct effect on the duration of hospitalization, patient satisfaction, and the level of stress and postoperative pain $[26,27]$. Previous studies gave priority to liver transplantation; however, recent studies have started addressing donor-related issues, such as mood changes, like depression and anxiety, and the quality of life. Mortality rate was reported as $0.2 \%$ for donors [28]. It is a substantial ratio and indicates that the quality of health should be ensured not only for recipients but also for donors. We believe that conducting intermittent meetings and regular follow-ups in the postoperative period will be useful in decreasing that ratio.

\section{Conclusion}

Many living donors are motivated to make their decision on this procedure in a short time. While donors were more anxious about surgical risks, recipients had higher anxiety about the risk of anesthesia-related mortality. Thus, it can be concluded that allocating more time to informing patients and donors and organizing information meetings on anesthesia and surgical procedures may be helpful in decreasing anxiety.

\section{References}

1. Uehara M, Hayashi A, Murai T, Noma S (2011) Psychological factors influencing donors' decision-making pattern in living-donor liver transplantation. Transplantation 92: 936-942.

2. Ladner DP, Dew MA, Forney S, Gillespie BW, Brown RS $\mathrm{Jr}$, et al. (2015) Long-term quality of life after liver donation in the adult to adult living donor liver transplantation cohort study (A2ALL). J Hepatol 62: 346-353.

3. Abecassis MM, Fisher RA, Olthoff KM, Freise CE, Rodrigo DR, et al. (2012) Complications of living donor hepatic lobectomy - A comprehensive report. Am J Transplant 12: 1208-1217.

4. Dew MA, Butt Z, Liu Q, Simpson MA, Zee J, et al. (2018) Prevalence and predictors of patient-reported long-term mental and physical health after donation in the adult-toadult living-donor liver transplantation cohort study. Transplantation 102: 105-118.

5. Ishizaki M, Kaibori M, Matsui K, Kwon AH (2012) Change in donor quality of life after living donor liver transplantation surgery: A single-institution experience. Transplant Proc 44: 344-346.

6. Pistorio $M L$, Veroux $M$, Trigona $C$, Patanè $M$, Lo Bianco $S$, et al. (2018) Psychological and emotional aspects in living donor kidney transplantation. Transplant Proc.

7. Wu MK, Hsu LW, Huang KT, Lin CC, Wang CC, et al. (2018) Assessment of relevant factors with respect to psy- 
chosocial properties in potential living donor candidates before liver transplantation. Neuropsychiatr Dis Treat 14: 1999-2005.

8. Russell RT, Feurer ID, Wisawatapnimit P, Salomon RM, Pinson CW (2008) The effects of physical quality of life, time, and gender on change in symptoms of anxiety and depression after liver transplantation. J Gastrointest Surg 12: 138-144.

9. Kugler C, Gottlieb J, Warnecke G, Schwarz A, Weissenborn K, et al. (2013) Health-related quality of life after solid organ transplantation: A prospective, multiorgan cohort study. Transplantation 96: 316-323.

10. Baranyi A, Krauseneck T, Rothenhäusler HB (2013) Overall mental distress and health-related quality of life after solid-organ transplantation: Results from a retrospective follow-up study. Health Qual Life Outcomes 11: 15.

11. López-Navas A, Rios A, Riquelme A, Martínez-Alarcón L, Pons JA, et al. (2010) Importance of introduction of a psychological care unit in a liver transplantation unit. Transplant Proc 42: 302-305.

12. Corruble E, Barry C, Varescon I, Falissard B, Castaing D, et al. (2011) Depressive symptoms predict long-term mortality after liver transplantation. J Psychosom Res 71: 32-37.

13. Jin SG, Xiang B, Yan LN, Chen ZY, Yang JY, et al. (2012) Quality of life and psychological outcome of donor after living donor liver transplantation. World J Gastroenterol 18: 182-187.

14. Noma S, Hayashi A, Uehara M, Uemoto S, Murai T (2011) Comparison between psychosocial long-term outcomes of recipients and donors after adult-to-adult living donor liver transplantation. Clin Transplant 25: 714-720.

15. Goebel S, Kaup L, Mehdorn HM (2011) Measuring preoperative anxiety in patients with intracranial tumors: The Amsterdam preoperative anxiety and information scale. $J$ Neurosurg Anesthesiol 23: 297-303.

16. Gras S, Servin F, Bedairia E, Montravers P, Desmonts JM, et al. (2010) The effect of preoperative heart rate and anxiety on the propofol dose required for loss of consciousness. Anesth Analg 110: 89-93.

17. López-Navas A, Ríos A, Riquelme A, Martínez-Alarcón L, Miras M, et al. (2010) Coping styles of patients on the liver transplant waiting list. Transplant Proc 42: 3149-3152.
18. Morana JG (2009) Psychological evaluation and follow-up in liver transplantation. World J Gastroenterol 15: 694-696.

19. Mavridou P, Dimitriou V, Manataki A, Arnaoutoglou E, Papadopoulos G (2013) Patient's anxiety and fear of anesthesia: Effect of gender, age, education, and previous experience of anesthesia. A survey of 400 patients. J Anesth 27: 104-108.

20. He K, Shen C, Chen X, Han L, Xi Z, et al. (2015) Health-related quality of life and sleep among Chinese children after living donor liver transplantation. Pediatr Transplant 19: 547-554.

21. Weng LC, Huang HL, Wang YW, Chang CL, Tsai CH, et al. (2012) The coping experience of Taiwanese male donors in living donor liver transplantation. Nurs Res 61: 133-139.

22. Simpson MA, Kendrick J, Verbesey JE, Morin DS, Dew MA, et al. (2011) Ambivalence in living liver donors. Liver Transpl 17: 1226-1233.

23. Narumi S, Umehara $M$, Toyoki $Y$, Ishido $K$, Kudo D, et al. (2012) Importance of awareness of perioperative social and physical situations of living donors for liver transplantation. Transplant Proc 44: 328-331.

24. Butt Z, Dew MA, Liu Q, Simpson MA, Smith AR, et al. (2017) Psychological outcomes of living liver donors from a multicenter prospective study: Results from the adult-to-adult living donor liver transplantation cohort study2 (A2ALL-2). American Journal of Transplantation 17: 1267-1277.

25. DuBay DA, Holtzman S, Adcock L, Abbey S, Greenwood S, et al. (2009) Adult right-lobe living liver donors: Quality of life, attitudes and predictors of donor outcomes. Am J Transplant 9: 1169-1178.

26. Stundner O, Kirksey M, Chiu YL, Mazumdar M, Poultsides L, et al. (2013) Demographics and perioperative outcome in patients with depression and anxiety undergoing total joint arthroplasty: A population-based study. Psychosomatics 54: $149-157$

27. Louis Onghena, Wouter Develtere, Carine Poppe, Anja Geerts, Roberto Troisi, et al. (2016) Quality of life after liver transplantation: State of the art. World J Hepatol 8: 749-756.

28. Trotter JF, Adam R, Lo CM, Kenison J (2006) Documented deaths of hepatic lobe donors for living donor liver transplantation. Liver Transpl 12: 1485-1488. 